pneumonia gradually disappeared, and the child was discharged on Jan. 14th, 1893, quite well, with no otorrhcoa, the wounds healed, and an increase of weight of one pound during the last fortnight of its stay in the hospital.

The diagnosis in the first of these cases was remarkably easy; the patient had symptoms of advanced pyærnia, with a foul otorrhoea, tender swelling over the deep vessels of the neck, and swollen optic dises. How long the septic thrombosis had existed is doubtful, but the case is of interest as indicating how radical treatment may save life even though the pyæmia may have reached an advanced stage. In the second case septic thrombosis of the sinus was only suspected when it was found that the small abscess cavity led through the mastoid vein aperture into the skull. In a patient so young (eleven months) the difficulties of both diagnosis and treatment are much increased, but it was remarkable how soon after the operation the child began to recover, and how rapidly convalescence took place. An early diagnosis, followed by prompt removal of the septic foci, is the correct treatment in such cases, and there is no reason to doubt that such treatment may be advantageously applied to other cases of like nature-e.g., umbilical pyæmia. In doubtful cases of middle ear disease, after exploring the mastoid antrum with a gouge, the exposure and examination of the lateral sinus and posterior fossa of the skull, whilst adding greatly to the risk, may succeed in preventing dangerous developments, especially in the case of extra-dural abscesses, which seem to remain latent for some time and then suddenly give rise to meningitis or lateral sinus mischief.

Albion-street, Hull.

\section{THE COURSE OF THE INFERIOR LARYNGEAL NERVE.}

By W. RAMSAY SMITH, M.B., C.M., B.Sc. Edin.

THE late Dr. Herbert Davies's paper on this subject in THE LANCET of Jan. 21st is one of those demonstrations that seem so neat, and the truth of which seems so desirable, that one hesitates to criticise them in case they should break down. As an eminent physician remarked to me recently regarding another physiological problem, "I should feel sorry if it were proved wrong, for it is such a pretty piece of physiology." I do not mean to say that Dr. Davies's demonstration is wrong, but I wish to point out one or two things pertinent to the subject that have to be considered before one can say that the explanation given can be said to be complete or proved. It appears to me that Dr. Davies's demonstration involves one or two assumptions that require proof, and one or two omissions that must be taken into the calculation. To take them seriatim they are:

1. The assumption, running through the whole argument, that respiration is a result of the combined action of the diaphragm and the muscles that open and close the rima glottidis. So far as regards quiet breathing this is not proved. The rima glottidis does not appreciably change its size and shape in normal breathing; and the recurrent largngeals are not necessary to ordinary breathing. Respiration can go on after section of both recurrent laryngeals, the rima glottidis having the patency it usually acquires only after death. It would seem, therefore, that so far as regards ordinary respiration such combined and concerted action between the phrenic and recurrent laryngeal nerves as Dr. Davies supposed does not necessarily occur, and it is questionable if it occurs at all. The whole demonstration might be made to turn upon this prime assumption and the proof of it. But in view of the interest that attaches to other parts of the paper I may be pardoned for passing on to them.

2. Suppose it were demonstrated that concerted action between the movements of the rocal cords and the diaphragm were necessary for respiration, the question arises, "Is this brought about by the correspondence in length between the phrenic and the recurrent laryngeal nerves?" Is it really necessary that the impulses, in order to be effective, should pass over the same length of nerve and reach the respective nerve terminations at the same instant of time? At first sight this seems to be a beautiful and exact demonstration; but two things have to be considered : The first is the difference in length between the right and left recurrent laryngeal nerves. The impulse by the right must reach the right side of the larynx at a moment appreciably in advance of the impulse that reaches the left side by the left nerve. This difference is considerable, as any one may calculate. The second consideration, which is to the same effect, is that in cases where the right inferior laryngeal nerve does not "recur" but passes straight to the larynx (I refer to the not uncommon condition where the right subclavian artery arises from the arch of the aorta) the proper ratio of lengths of the right and left inferior laryngeals and the phrenics is enormously changed, and yet respiration and voice production go on as usual.

3. Another assumption, a very common one, that seems at first sight self-evident, is that the phrenic nerve by its distribution, in the human body, on the inferior surface of the diaphragm is less subject to pressure than if it were distributed on the upper surface. This may or may not be true, but I imagine that any theory, at any rate, the ordinary. theory, advanced to prove it will be found to involve a nice fallacy in physics.

These three considerations, it appears to me, must be taken into account in estimating the value of Dr. Davies's posthumous contribution. I would add another-viz., the concerted action between the muscles supplied by the superior and the recurrent laryngeal nerves. The subject of the simultaneous innervation of antagonist muscles, especially those concerned in making delicate movements, is almost entirely overlooked in our text-books and in our teaching, but it furnishes the key to a great many difficult problems.

I am not prepared to say that the course of the recurrent laryngeal nerve is not to be explained with reference to the concerted action between the muscles supplied by it and the diaphragm supplied by the phrenic, but it seems to me that Dr. Davies's theory that it is to be so explained involves as many difficulties, if not more, than does the theory that the relative lengths of these nerves have nothing to do with the matter.

Theories of this description are very fascinating. They are often wrong, but criticism of them not infrequently points the way to a truer explanation. The works of old masters in science, medicine and philosophy are full of them, some fanciful in the extreme, some evidently erroneous, some seemingly true, yet all requiring rigorous testing. To mention many of those theories would be tedious and useless. I may take, however, from my note-books a few instances of theories taught even now that have probably as little foundation in fact as the theories that have been exploded ages ago :

1. Normal knock-knee in women is said to be due to the greater width of the pelvis. Let it be granted that the pelvis is wider in women, as it is granted that women possess ovaries : how does width of pelvis explain knock-knee? Does width of pelvis explain the greater degree of knock-elbow in women ?

2. In the act of swallowing, the lower jaw, it is said, is firmly applied to the upper. This is said to be necessary in order that the muscles attached to the lower jaw may have a fixed point to act from. But swallowing is possible without fixing the lower jaw to the upper. It is not possible, however, without fixing the tongue.

3. Spigelius says that the function of the buttocks is to form a cushion on which the body may be softly supported, for the purpose of divine cogitation. Is there any real advance on this theory?

4. It is taught that the great preponderance of muscles inserted on the inner aspect of the tibia is to be explained in relation to the unscrewing of the knee-joint at the beginning of the movement of flexion. I have examined this theory in the Journal of Anatomy and Pleysiology, and have ventured an explanation that may also cast some light upon the function of the buttocks.

5. The "reflex pain" in the knee in cases of hip-joint disease is explained by the fact that the obturator nerve supplies both. Is this a real explanation? In this connexion I may state that I have found that stimulation of a spot of skin about an inch to the left of the external occipital protuberance is associated with a corresponding sensation at the same instant, referred to a spot just over the tip of the twelfth rib on the left side.

These are only a few instances, but they illustrate how very necessary it is to apply a little logical criticism to every theory in anatomy and physiology, however well established it may appear to be. Medical science appears to suffer more from want of well-trained minds than from want of the spirit of investigation.

Inverleith-gardens, Edinburgh. 